\title{
Challenges of Implementing Depression Care Management in the Primary Care Setting
}

\author{
Bea Herbeck Belnap, ${ }^{1,8}$ Julie Kuebler, ${ }^{2}$ Carole Upshur, ${ }^{3}$ Kevin Kerber, ${ }^{4}$ \\ Deborah Ruth Mockrin, ${ }^{5}$ Amy M. Kilbourne, ${ }^{6}$ and Bruce L. Rollman ${ }^{7}$
}

\begin{abstract}
Empirical evidence shows that care management is an effective tool for improving depression treatment in primary care patients. However, several conceptual and practical issues have not been sufficiently addressed. This article explores questions concerning the scope of care management services within the chronic illness care model; optimal ways to identify depressed patients in the primary care setting; responsibilities and desirable qualifications of depression care managers; the location and manner in which care managers interact with patients; costs of services provided by care managers; and the level of supervision by mental health specialists that is necessary to ensure quality care.
\end{abstract}

KEY WORDS: care management; depression; primary care.

\section{BACKGROUND}

Although evidence-based guidelines for the treatment of depression in primary care were published as early as 1993 by the Agency for Health Care Policy and Research, depression continues to be underdiagnosed and inadequately treated. In an effort to close what the Institute of Medicine (2001)

${ }^{1}$ Center for Research on Health Care, School of Medicine, University of Pittsburgh, Pittsburgh, PA.

${ }^{2}$ University of Michigan Department of Psychiatry, University of Michigan Health Systems, Ann Arbor, MI.

${ }^{3}$ Department of Family Medicine and Community Health, University of Massachusetts Medical School, Worcester, MA.

${ }^{4}$ University of Michigan Department of Psychiatry, University of Michigan Hospitals and Health Centers, Ann Arbor, MI.

${ }^{5}$ Department of Family Medicine and Community Health, University of Massachusetts Medical School, Worcester, MA.

${ }^{6}$ VA Pittsburgh Center for Health Equity Research and Promotion and the Center for Research on Health Care, School of Medicine, University of Pittsburgh, Pittsburgh, PA.

${ }^{7}$ Center for Research on Health Care, School of Medicine, University of Pittsburgh, Pittsburgh, PA.

${ }^{8}$ Correspondence should be directed to Bea Herbeck Belnap, Dr., Biol. Hum., University of Pittsburgh School of Medicine, Center for Research on Health Care, Suite 600, 230 McKee Place, Pittsburgh, PA 15213-2582; e-mail: belnapbh@upmc.edu. called the "quality chasm" between the usual care of chronic illnesses and the appropriate care of these illnesses, researchers have instituted numerous studies.

The first wave of studies that focused on depression tried to close the chasm by giving guideline-based feedback to primary care physicians (PCPs) about their patients who required depression care. However, this single measure of feedback to PCPs did not result in significant improvement of depression recognition or treatment, nor did other single-measure interventions, such as the use of patient screening or patient registries (Gilbody, House, \& Sheldon, 2001; Goldberg et al., 1998; Rollman et al., 2002; Schulberg, Katon, Simon, \& Rush, 1998). Even after improvement in depression recognition, treatment remained suboptimal, with physicians prescribing inadequate dosages and durations of antidepressant therapy, patients failing to comply with treatment recommendations, and patients having limited access to psychotherapy (Simon, \& VonKorff, 1995; Wells, Schoenbaum, Unützer, Lagomasino, \& Rubenstein, 1999).

The second wave of studies tried to close the chasm by offering more sophisticated models of 
depression care. The stepped care model pioneered by Katon et al. (1996) combined various interventions, including education of PCPs about appropriate (evidence-based) depression care, education of patients about adherence to treatment regimens, and measures designed to encourage collaboration between PCPs and mental health specialists. Studies demonstrated that patients whose treatment was based on this model were more likely to show an improvement in depression outcomes than were patients who received care as usual (Katon et al., 1995, 1996). Wagner's Chronic Care Model (VonKorff, Gruman, Schaefer, Curry, \& Wagner, 1997; Wagner et al., 1996) emphasized collaboration among various physician and nonphysician healthcare professionals and expanded the earlier model to include other factors pertinent to effective care, such as buy-in by leadership, redesign of the delivery system, improvement of the clinical information system to facilitate patient follow-up, institution of patient self-management support, and linkage of patients with community resources.

Within the collaborative care model, several variations of programs managed by nurses and other nonphysicians (care managers) have evolved. These programs have differed in terms of the care manager's background and training, types of services offered, predominant mode of interaction with patients (by telephone or in person), and location and linkage with the primary care office. Although in some cases the care manager has been expected to do little more than provide brief patient education and medication counseling, in other cases the care manager has assumed a highly active role in a multifaceted intervention that includes counseling. To date, we know of eight published randomized controlled studies that have assigned nonphysicians a major proactive role in the depression treatment plan, primarily by redefining the role of primary care nurses and integrating mental health professionals into primary care settings (see Table 1 ).

In the study of Wells et al. (2000), nurses screened patients in primary care clinics for depressive symptoms, and study investigators then randomized patients with major or minor depressive disorders to receive either usual care, medication, or individual or group psychotherapy, with care managers following the patients in the group receiving medication and helping with referrals for the psychotherapy group. In the study of Katzelnick et al. (2000), investigators instituted depression screening for high utilizers of health care services and initiated treatment for those diagnosed with depression. Care managers employed by the health plan contacted the patients with depression by telephone to promote adherence to medications and to help patients with coordination of their health care. In the studies of Oxman, Dietrich, \& Schulberg (2003) and Simon, VonKorff, Rutter, \& Wagner (2000), care managers also followed up on depressed patients via telephone to increase adherence to medications. Care managers in the study of Hunkeler et al. (2000) provided telephone support not only by promoting treatment adherence but also by encouraging patients to attend peer group support sessions. In other studies (Bruce et al., 2004; Rost, Nutting, Smith, \& Werner, 2000; Unützer et al., 2002), care managers provided both telephone and face-to-face support to patients. In addition to promoting medication adherence, care managers in the study by Unützer et al. (2002) offered problem-solving treatment, and care managers in the study of Bruce et al. (2004) offered interpersonal psychotherapy.

All eight studies showed that the collaborative intervention decreased the patients' symptoms of depression, and all but one study (the study of Hunkeler) showed that the intervention increased the patients' adherence to treatment. These results were confirmed by a recent meta-analysis of 24 disease management programs for depression (Badamgarav et al., 2003). In this meta-analysis, pooled estimates showed that patients in the programs had an increase in the number of primary care visits. Costs for care management were reported in only a few studies and ranged from $\$ 61$ per patient (Rost et al., 2000) to $\$ 553$ per patient (Unützer et al., 2002).

\section{A Blueprint for Depression Care Management}

Based on the chronic care model of Wagner and colleagues (1996, 1999) and the findings in the studies described above, the clinical consultants for the Robert Wood Johnson Foundation (RWJF) "Depression in Primary Care" Incentive Project (Pincus, Pechura, Elinson, \& Pettit, 2001) developed a blueprint for the implementation of depression care management in the primary care setting (Kilbourne et al., 2002).

The eight demonstration sites involved in the project were required to develop protocols that included the following: the systematic identification of patients at increased risk for depression; the use of a 
Table 1. Studies of Collaborative Care for Depression

\begin{tabular}{|c|c|c|c|c|c|c|}
\hline Study & $\begin{array}{l}\text { Background } \\
\text { of } \\
\text { Care Manager* }\end{array}$ & $\begin{array}{l}\text { Form of Contact } \\
\text { with Patients }\end{array}$ & Intervention & $\begin{array}{c}\text { Self- } \\
\text { Management } \\
\text { Support }\end{array}$ & $\begin{array}{l}\text { Mental Health } \\
\text { Services }\end{array}$ & Environment \\
\hline $\begin{array}{l}\text { Wells et al., } \\
2000\end{array}$ & Nursing & In person & $\begin{array}{l}\text { Medication } \\
\text { adherence; } \\
\text { cognitive } \\
\text { behavioral } \\
\text { therapy }\end{array}$ & Education & $\begin{array}{l}\text { Supervision; } \\
\text { consultation }\end{array}$ & $\begin{array}{l}\text { Health } \\
\text { maintenance } \\
\text { organization } \\
\text { (HMO) } \\
\text { primary care }\end{array}$ \\
\hline $\begin{array}{l}\text { Katzelnick } \\
\text { et al., } 2000\end{array}$ & $\begin{array}{l}\text { Social work or } \\
\text { psychology }\end{array}$ & By telephone & $\begin{array}{l}\text { Medication } \\
\text { adherence; } \\
\text { treatment } \\
\text { coordination }\end{array}$ & Education & Consultation & Health plans \\
\hline $\begin{array}{l}\text { Simon et al., } \\
2000\end{array}$ & $\begin{array}{l}\text { Social work or } \\
\text { psychology }\end{array}$ & By telephone & $\begin{array}{r}\text { Medication } \\
\text { adherence }\end{array}$ & Education & Supervision & $\begin{array}{l}\text { Group } \\
\text { practice } \\
\text { primary care }\end{array}$ \\
\hline $\begin{array}{l}\text { Oxman } \\
\text { et al., } 2003 \dagger\end{array}$ & $\begin{array}{l}\text { Nursing, social } \\
\text { work, or psychology }\end{array}$ & By telephone & $\begin{array}{r}\text { Medication } \\
\text { adherence }\end{array}$ & Education & Supervision & $\begin{array}{l}\text { Multisite } \\
\text { primary care }\end{array}$ \\
\hline $\begin{array}{l}\text { Hunkeler } \\
\text { et al., } 2000\end{array}$ & Nursing & By telephone & $\begin{array}{l}\text { Medication } \\
\text { adherence; } \\
\text { peer support } \\
\text { groups }\end{array}$ & Education & Supervision & $\begin{array}{l}\text { Managed care } \\
\text { primary care }\end{array}$ \\
\hline $\begin{array}{l}\text { Rost et al., } \\
2000\end{array}$ & Nursing & $\begin{array}{l}\text { By telephone } \\
\text { and in person }\end{array}$ & $\begin{array}{l}\text { Treatment } \\
\text { adherence }\end{array}$ & Education & Training & $\begin{array}{l}\text { Community } \\
\text { primary } \\
\text { care clinics }\end{array}$ \\
\hline $\begin{array}{l}\text { Unützer } \\
\text { et al., } 2002\end{array}$ & Nursing & $\begin{array}{l}\text { By telephone } \\
\text { and in person }\end{array}$ & $\begin{array}{l}\text { Medication } \\
\text { adherence; } \\
\text { problem-solving } \\
\text { treatment }\end{array}$ & Education & $\begin{array}{l}\text { Supervision; } \\
\text { consultation for } \\
\text { treatment-resistant } \\
\text { patients }\end{array}$ & $\begin{array}{l}\text { Multisite } \\
\text { primary care }\end{array}$ \\
\hline $\begin{array}{l}\text { Bruce } \\
\text { et al., } 2004\end{array}$ & $\begin{array}{l}\text { Nursing, } \\
\text { social work, or } \\
\text { psychology }\end{array}$ & $\begin{array}{l}\text { By telephone } \\
\text { and in person }\end{array}$ & $\begin{array}{l}\text { Medication } \\
\text { adherence; } \\
\text { interpersonal } \\
\text { psychotherapy }\end{array}$ & Education & Supervision & $\begin{array}{l}\text { Multisite } \\
\text { primary care }\end{array}$ \\
\hline
\end{tabular}

*Social workers or psychologists had a bachelor's or master's degree.

$\dagger$ Although some data concerning the Oxman study are available, the results have not yet been published.

structured assessment tool (preferably the 9-item Patient Health Questionnaire, or PHQ-9, Kroenke, Spitzer, \& Williams, 2001) to screen patients at increased risk for major depression; the stratification of treatment intensity by episode, severity, and patient preference; the monitoring of symptoms of depression and suicidality; the promotion of guideline-based treatment for depression; the implementation of routine follow-up at intervals based on the patient's phase of depression treatment (acute care, continued treatment, and maintenance); supervision or consultation with a mental health specialist; and assistance with mental health referral and access.

During the start-up phase, each of the demonstration sites faced a series of challenging questions: (1) What tasks should the care managers perform? For example, should they be responsible for some or all of the screening for depression, or are there more cost-effective ways to identify depressed patients? Although there is evidence that care management can increase the patients' compliance with treatment and decrease their symptoms of depression (Badamgarav et al., 2003), how much patient support should be offered by care managers? (2) What qualifications should care managers have? Should they be nurses? How much mental health training do they need? (3) Where should the care managers be located? Should they work in a primary health care office, a central location, or both? And to whom should 
they ultimately be accountable? (4) Should the care managers' contacts with the patients be by telephone, in person, or both? And how often should they contact the patients? (5) To what extent should a mental health specialist be involved in care management? How much supervision of care manager activities is necessary?

In the following section, we present examples of how the planners at two program sites-the University of Michigan and the University of Massachusetts-answered these questions and handled additional challenges in customizing their care management program to meet the needs of their patients and to ensure that the program would be sustainable beyond the funding phase.

\section{CASE STUDY 1: UNIVERSITY OF MICHIGAN}

\section{Project Description}

In 1998, two large local employers invited the University of Michigan to help develop disease management programs for their employees with chronic illnesses. In response, the University of Michigan Medical Management Center founded and funded the Michigan Depression Outreach and Collaborative Care (MDOCC) Program, which began enrolling patients in May 2001 and became part of the RWJF "Depression in Primary Care" Incentives Project in November 2002.

The MDOCC Program considers depression care management to be a process that supplements usual clinical operations and is designed to improve the quality of care and to ensure continuity of care. The care managers in the program function as information, risk, and quality assurance managers.

\section{Roles and Responsibilities of Depression Care Managers}

In the typical case, a PCP contacts the designated care manager, by telephone, e-mail, or faceto-face meeting, to refer a current patient requiring further depression assessment or management. (In some cases, however, the PCP sends a list of patients for the care manager to call and enroll ["cold calls"]). After receiving a referral, the care manager gathers clinical data from the medical record, enters basic patient information into the MDOCC database, and telephones the patient to explain the program and invite the patient to enroll. Most care manager contacts with patients are by telephone and patients are stratified into three levels of care (see Table 2). Although the PCP can assign patients to a specific level at the time of referral, not all PCPs are familiar with the stratification criteria of the threelevel system, so the care manager typically stratifies most patients after the initial enrollment contact.

At their first telephone contact, the care managers always identify themselves as a member of the PCP's treatment team and then (1) reiterate that depression is a chronic recurrent illness requiring adherence to treatment guidelines and long-term monitoring of symptoms; (2) emphasize that the care manager's role is to provide assistance in the form of education, monitoring, and support but not to replace the care given by the PCP; (3) review the patient's current need for information about depression and arrange for individualized educational materials and basic program information to be sent to the patient; (4) assess the patient's current risk of suicide and recurrent depression; (5) answer questions that the patient may have at this point; (6) introduce self-management principles; (7) indicate that a care manager will contact the patient again by telephone in 1 month for follow-up but encourage the patient to contact the MDOCC office sooner if questions arise; and (8) transfer the patient to an interactive voice recognition (IVR) system that allows the patient to complete baseline outcome measures, including an 8-item Patient Health Questionnaire (PHQ-8).

During the second telephone call, the care manager (1) reinforces the messages of the first call; (2) provides individualized instruction concerning self-management; (3) encourages the patient to discuss specific concerns about depression and health care; (4) provides problem-solving assistance or information on local resources; and (5) completes another clinical assessment. The care manager faxes or e-mails the PCP a copy of the patient's assessment and recommends additional consultation or treatment services that may be needed after each call. If it appears that a patient requires immediate contact with the PCP, the care manager assists the patient in scheduling an appointment. MDOCC care managers initiate from 40 to 60 patient contacts per week per care manager, with contacts falling into initial patient enrollment calls, follow-up calls, and support or crisis calls. If patients fail to respond to three phone messages, they are removed from the 
Table 2. Levels of Depression Management (MDOCC)

\begin{tabular}{|c|c|c|c|}
\hline Level & Treatment Phase & Criteria & Clinical Interventions \\
\hline 1 & Routine maintenance & $\begin{array}{l}\text { Stable patients who need lonly long-term } \\
\text { monitoring or whose principal physician } \\
\text { wishes to provide primary treatment }\end{array}$ & $\begin{array}{l}\text { Case Manager monitors and provides } \\
\text { appropriate intervention to address } \\
\text { the following: } \\
\text { - Treatment adherence } \\
\text { - Compliance with HEDIS criteria }\end{array}$ \\
\hline 2 & $\begin{array}{l}\text { Treatment of uncomplicated } \\
\text { patients in acute episode or } \\
\text { maintenance of complicated } \\
\text { patients }\end{array}$ & $\begin{array}{l}\text { Patient characteristics: } \\
\text { - MDD diagnosis } \\
\text { - May have significant } \\
\text { recurrence risk } \\
\text { - Patient outcome relatively } \\
\text { stable despite complications } \\
\text { listed below; good adherence; } \\
\text { step-down from level } 3\end{array}$ & $\begin{array}{l}\text { Case Manager monitors and provides } \\
\text { appropriate intervention to address } \\
\text { the following: } \\
\text { - Treatment adherence } \\
\text { - Compliance with HEDIS criteria } \\
\text { - Treatment adequacy using } \\
\text { treatment guidelines } \\
\text { - Side effects } \\
\text { - Patient education needs } \\
\text { - Appropriateness of level of care }\end{array}$ \\
\hline 3 & $\begin{array}{l}\text { Acute treatment of compli- } \\
\text { cated patients }\end{array}$ & $\begin{array}{l}\text { MDD diagnosis in acute phase, with any } \\
\text { of the following complications: } \\
\text { - Treatment resistance } \\
\text { - Three or more psychotropics } \\
\text { - Alcohol or substance abuse } \\
\text { - Problems with benzodiazepine use } \\
\text { - Postpartum psychosis } \\
\text { - History of psychiatric } \\
\text { hospitalization } \\
\text { - History of disability } \\
\text { - Serious suicide risk } \\
\text { - Severe medical/psychiatric } \\
\text { comorbidity } \\
\text { - High cost/utilization of med/surg } \\
\text { or psychiatric services } \\
\text { - High severity or acuity }\end{array}$ & $\begin{array}{l}\text { Case Manager monitors all of the above } \\
\text { and provides the following additional } \\
\text { services: } \\
\text { - Facilitates family interventions } \\
\text { - Provides crisis management } \\
\text { - Provides case management } \\
\text { - Facilitates subspecialty consultation }\end{array}$ \\
\hline
\end{tabular}

active list but are sent a letter inviting them to call or return their assessments by mail. A response to the letter places them back on the active list. The care managers encourage patients to remain actively involved in their care by sending each patient a packet of information after every scheduled call. The information includes an outcome summary report with a graph of the patient's most recent PHQ-8 scores, an individual self-management goal, and a reminder to look for common depressive symptoms and to continue taking medications. The summary report has been well received and has helped keep patients interested and active in the program.

\section{Qualifications of Depression Care Managers}

At the outset of the MDOCC program, the staff agreed that individuals with diverse educational backgrounds in a variety of disciplines could assume the role of care manager. However, as the role evolved and became more complex, there have been multiple discussions about qualifications and some revisions in thinking. In practice, care managers with extensive psychiatric experience and advanced degrees have proved to be most clinically effective, but not most cost-effective. Therefore, MDOCC has considered using different levels of care managers to perform different tasks. For example, while a more experienced care manager could be used to conduct initial patient contact, assessment, and education, a less experienced care manager could handle routine monitoring. MDOCC has considered using an advanced practice psychiatric nurse to provide consult-liaison services to PCPs, institute interventions for patients with more complex problems, and offer ongoing assistance and supervision to care managers. 


\section{Integration of Depression Care Managers into Primary Care Sites and Practices}

MDOCC care managers are located at a central site on the main hospital campus and make site visits with the goal of improving their and the program's visibility, answering questions, providing direct feedback to clinicians, offering self-management education to groups of patients, and providing clinician education regarding depression treatment.

PCPs showed mixed responses and various degrees of interest to the MDOCC care managers concerning the program. Despite the initial intense and frequent contacts of care managers with PCPs at the various sites, the PCPs often appeared to be uncertain about the kinds of services the program provides. The most common misconception is that the care managers will take over, rather than supplement, the care of the patients. Many PCPs involved with the program lack information or experience regarding the diagnosis and treatment of depression. Therefore, the care managers inform them by first discussing depression management with all PCPs when introduced to the program. Second, they include information about depression management in an MDOCC Program newsletter that is sent periodically to the PCP sites. Third, if individual PCPs request additional information, the care managers facilitate their interaction with the MDOCC psychiatrist or psychiatric nurse practitioner. Fourth, when the care managers contact PCPs to give them feedback about their patients who have enrolled in the program, the care managers make guideline-based recommendations regarding treatment for each patient.

\section{Funding and Costs of Services Provided by Depression Care Managers}

The University of Michigan has five disease management programs (in asthma, congestive heart failure, coronary artery disease, diabetes, and depression). The MDOCC Program is the largest and has become an integral part of the new University of Michigan Depression Center. In 2002, when it began to enroll all new depression center patients, a second care manager was hired, with the salary funded by the Department of Psychiatry. When the RWJF "Depression in Primary Care" project commenced, a third care manager was hired in the summer of 2003 and a fourth in the fall of
2003, with one of the salaries funded by the RWJF grant and the other covered by the Department of Psychiatry.

The MDOCC Program tracks the time and services of each care manager for the purpose of documenting the 500 separate care management contacts and other activities a month. Despite the fact that most insurance companies do not reimburse for care management activities, the information is tracked in order to document care manager productivity and to make a case for possible future reimbursement.

\section{Future Directions of the MDOCC Program}

The value of specific care management services will need to be demonstrated. This will require the continuous collection and assessment of outcome data and its analysis in light of specific care manager functions and services. In this time of ubiquitous budgetary constraints, disease management programs will need to demonstrate acceptable costeffectiveness (though not necessarily the wished-for cost offset). The challenge will be to use this information both internally, as part of ongoing quality improvement and re-design, and externally, as a way of responding to the growing demand for such services from payors and employers.

\section{CASE STUDY 2: UNIVERSITY OF MASSACHUSETTS}

\section{Project Description}

In the spring of 2003, the Commonwealth of Massachusetts Medicaid Program (MassHealth), in collaboration with the Massachusetts Consortium on Depression in Primary Care (MCDPC) and the Department of Family Medicine and Community Health at the University of Massachusetts Medical School, initiated depression care management as part of the RWJF "Depression in Primary Care" Incentives Project. The MCDPC Program targets categorically eligible Medicaid adults aged 18-65, primarily young parents receiving temporary assistance for needy families (TANF), and other adults who qualify for Medicaid because they have a low income and chronic illness. The MCDPC Program provides screening, assessment, treatment, and the services of a depression care manager. During the 
first year of the program, 809 patients completed a PHQ-9 questionnaire and care management was offered primarily to those patients with indications of major depression (a PHQ-9 score of 15 or higher). A total of 207 patients became eligible for care management services using these criteria.

\section{Roles and Responsibilities of Depression Care Managers}

MCDPC Program care managers are responsible for providing patients with support and encouragement, monitoring their depression symptoms and their compliance with pharmacologic and/or behavioral treatment, helping them to learn and engage in self-management skills and to obtain referrals to behavioral health specialists and community resources, and serving as a link between patients and their PCPs and behavioral health specialists.

Program staff developed a written care manager manual that identifies each step of the depression screening and referral process, the frequency of contact, the goals for different stages of treatment, and the specific activities expected of the care manager at each patient contact. This manual reviews risk assessment, includes contact information for local behavioral health providers that accept patients with MassHealth insurance, and provides a guide to community resources for referrals for other needs. The program staff also developed a database that shows activities related to each patient, including contacts in person, by telephone, and through collateral work. In addition to recording the time spent in each activity for each patient, care managers periodically and systematically record their administrative and paperwork hours so that the average amount of time spent in the various functions can be estimated.

Each care manager meets once a week with a clinical site manager to address both clinical and program implementation issues and barriers. In addition, each care manager has access to a psychiatrist to review cases and be available on an on-call basis for urgent consultation. Monthly cross-site team meetings are conducted to review progress and discuss solutions to problems. On a quarterly basis, the care managers, the PCPs, the administrators from each participating primary care office, the behavioral health providers, and the insurance plan administrators meet for a half-day discussion and didactic sessions about treating depression in primary care.
Because Medicaid patients are less connected to the medical care system, often have less structured lives, and are at times suspicious of health care, social service, and mental health providers, the planners felt strongly that the program should offer the option of face-to-face visits between care managers and patients to help establish trust and facilitate effective communication. While preliminary work demonstrated that most patients could be accessed by telephone, building a personal relationship through face-to-face contact was still viewed as important to overcoming other barriers to providing appropriate care.

When a patient is diagnosed with depression and referred to the MCDPC Program, the guidelines indicate that a care manager should contact the patient by telephone within 1 week of diagnosis, see the patient within 2 weeks, and establish a schedule in which visits occur every 3 months and phone contacts are made between visits. However, since few patients can be reached on a prearranged schedule (many are not regularly at home, some do not answer their phone, and others do not return messages), the care managers adjust their follow-up schedules as necessary. Most patients receive fewer face-to-face visits and completed telephone calls than anticipated. After 3 to 5 missed contacts with a patient, the care manager sends the patient a letter (with a copy to the PCP) to encourage the patient to get in touch if assistance is needed. At that point, the patient is placed in an inactive file, but the case can be reactivated upon contact by the patient. In addition to working directly with patients, care managers spend much of their time arranging for collateral services and consulting with PCPs and behavioral health specialists on behalf of the patients. For some patients, it is necessary to organize an extensive array of social service supports, such as securing transportation for medical appointments, obtaining child care, dealing with abusive partners, and finding better housing.

\section{Qualifications of Depression Care Managers}

During the planning phase, the program developers felt that the care managers should have a professional health care background that was adequate for negotiating with PCPs concerning patient care, so they did not consider paraprofessionals or individuals with a bachelor's degree. They originally thought that nurses would be best 
for the role, since nurses could be trained to manage depression and would already have experience with issues concerning chronic disease management and patient education and support. However, the program developers ultimately decided that licensed, independent clinical social workers (LICSW) might be the most useful care managers. First, the LICSW would be able to address complex psychosocial and mental health issues with the patients. Second, the LICSW would have enough behavioral health expertise to handle patients in most cases and would need less supervision and backup. Third, the LICSW could work independently, both legally and fiscally, allowing clinical sites that did not have mental health clinic status to establish a contractual relationship to support the care manager role.

For one of the sites, the program developers did hire an LICSW who had experience in managed care utilization review. For a site with a predominantly Latino patient population, they were unable to find a bilingual LICSW. Instead, they hired a bilingual nurse who had experience as a chronic illness care manager.

Regardless of their background, the care managers find that working with Medicaid patients is challenging. In addition to having symptoms of depression, the patients frequently have comorbid illnesses, behavioral health problems, and social problems. Many are reluctant to interact with the care manager, are difficult to locate, and are resistant to following through with care recommendations. Of the patients referred to the depression care managers, over $45 \%$ have experienced physical or sexual abuse as an adult, over $40 \%$ were abused during childhood, $14 \%$ report substance abuse, $60 \%$ report comorbid panic attacks, and $45 \%$ report comorbid anxiety attacks. About $3 \%$ have a history of schizophrenia, $11 \%$ have a history of bipolar disorder, and over $70 \%$ have a prior history of depression. The MCDPC database also shows that $60 \%$ of the patients referred for depression care management have at least one comorbid chronic medical condition and that the most prevalent conditions are asthma, hypertension, and diabetes. Thus, in addition to addressing issues related to depression, care managers address issues concerning the overall health of each patient, including adherence to treatment for other chronic illnesses, keeping all medical appointments, and implementing self-help tasks.

\section{Integration of Depression Care Managers into Primary Care Sites and Practices}

Before the program was begun, selected PCPs attended focus groups to discuss their experiences with and expectations for care management. They indicated that prior care management models seemed ineffective and often left the PCPs out of the communication loop. Instead, a co-location of care managers at primary care sites would emphasize primary care teamwork and allow greater interaction with reluctant patients. However, the commitment of a full-time care manager to a primary care site would be justified only if there were a large enough potential caseload.

In a high-volume community health center in which over $50 \%$ of the patients were insured by Medicaid, preliminary screenings indicated that the prevalence of depression was high enough to justify having a full-time depression care manager. In other settings, such as hospital outpatient clinics and small group practices, the percentage of patients insured by Medicaid and the prevalence of depression were not high enough to justify a full-time care manager. Therefore, it was necessary to assign a care manager to work with multiple sites in a relatively small geographic area. Although this "circuit judge" model is preferable to the insurance-based or planbased model in which care managers are responsible for a wide geographic area, it is not optimal. It requires the care manager to spend a lot of time building and rebuilding relationships with the clinics and group practices.

\section{Funding and Costs of Services Provided by Depression Care Managers}

Planners projected a total of 9-17 contacts per year for each patient, depending on the severity of the patient's symptoms. They estimated the reimbursable rate for each type of contact, based on existing codes and rates, and projected a cost of $\$ 244$ to $\$ 365$ per year per patient. They also estimated that each care manager would spend 25 hours a week in reimbursable activities, while the balance would be spent in paperwork, training, and administrative tasks. Based on these assumptions, they determined that a LICSW care manager would be able to handle a caseload of about 200 patients and that the amount of reimbursement from billable 
services would be almost enough to cover the care manager's salary and fringe benefits.

Early experience with the program shows that the care managers are spending an average of 18 hours a week performing patient-directed services that are potentially reimbursable. The fact that they are spending more hours than originally anticipated fulfilling tasks related to program administration and implementation in primary care practices is largely due to the need to resolve start-up issues and establish a smoother flow from primary care screening to referrals for care management. In the site with a high volume of Latino patients, the care manager had to spend more time than anticipated helping patients with literacy problems to self-administer the PHQ-9 and to use some of the patient education materials. Although each care manager is currently responsible for about 70 active patients, the MCDPC administrators anticipate care managers to adequately handle an active caseload of well over 100 patients in the future, when the load is more balanced with a combination of stable and new patients.

\section{Summary of the Massachusetts Experience}

In developing the roles for care managers, the program planners adapted certain aspects of prior work to meet the particular needs of the ethnically and racially diverse population they were targeting. They learned that care managers need clear direction and regular supervision and that guidelines, rather than specific performance objectives, were necessary to carry out their activities effectively when dealing with challenging patients and coordinating activities involving a variety of health care and social services. While the outcome analysis is in its early stages, the program staff has already documented significant decreases in patient depression scores at follow-up reassessments. It seems clear that the care management role has kept the majority $(65 \%)$ of patients in care and at reasonable cost. As the program matures, the staff and care managers expect to continue to explore the costs and benefits associated with depression care management and to learn how to best structure the care management role.

\section{LESSONS LEARNED}

As these case studies depict, the tasks and responsibilities of depression care managers require a high degree of professional flexibility and skill. The qualifications required for the job vary, depending on the patient population served. Programs that target patients with severe depression and several concomitant medical conditions tend to hire nurses. Programs whose depressed patients have complex psychosocial issues fare better with social workers, while programs that provide counseling to depressed patients with comorbid behavioral disorders prefer care managers with strong backgrounds and experience in mental health care.

The central component of the care manager's role is to ensure that patients with chronic disorders have adequate symptom monitoring and follow-up care. This requires the care manager to work closely with PCPs. However, behaviorally oriented care managers often experience difficulty adequately engaging PCPs in their patients' depression care. Locating the care manager in the primary care site increases the opportunities for acceptance by and communication with PCPs and patients, but an on-site location is not always feasible given space, patient volume, and financial constraints. Communications regarding the progress of patients must be customized to the PCPs' needs and should ideally be timed so that the information is easily linked with patient visits. As the above case studies indicate, faxes, e-mails, and other types of communication have been tried as venues. The inclusion of care manager reports in the patients' electronic medical records has been proposed at the University of Michigan and implemented at the University of Pittsburgh (Rollman, Belnap, Reynolds, Schulberg, \& Shear, 2003).

\section{IMPLICATIONS FOR POLICY AND PRACTICE}

Ample empirical evidence demonstrates that care management is an effective tool for improving depression treatment in primary care patients. However, several conceptual and practical issues have not been sufficiently addressed or resolved. Successfully sustaining the contribution of depression care management services to the improved outcomes of primary care depression treatment depends, in large part, on the decisions made by key policy and opinion leaders in regard to the issues raised below.

First, it is important to clarify the scope of care management services within the chronic illness care 
model. The extent of cross-comorbidity within the spectrum of chronic disease states (diabetic patients with major depression, seriously depressed patients with cancer, etc.) is increasingly appreciated as the rule rather than the exception. Three care management models exist to serve these populations. In the "separate" model (primarily used in the case studies presented here), the care manager is responsible for a single condition. This model has been shown to be effective in research but does not meet the demands of primary care practices with heterogeneous patient groups. In the "blended" model, the care manager is responsible for one or more comorbid conditions that are managed simultaneously. And in the "braided" model, the care manager is responsible for one or more concurrent conditions that are prioritized according to severity and are treated consecutively. Since many depressed primary care patients have more than one chronic disease, it seems worthwhile to pursue either the blended or the braided model. But it is not clear what qualifications and training care managers would need for these two models, nor is it clear who the appropriate supervisor would be, since a specialist for every condition would not be feasible.

Second, care manager roles and responsibilities also require clarification for quality assurance and to increase the likelihood of third-party reimbursement. In both case studies, the list of responsibilities included many tasks that could be done by other less well-trained individuals but were assigned to care managers nevertheless. This fills the care manager's schedule with non-reimbursable activities. Much of the care manager's reimbursable time and effort is dedicated to educating patients and motivating their adherence to treatment regimens. The development and adoption of evidence-based care management processes would facilitate payment for care management services.

Third, it is necessary to develop better process and outcome measures of care management services to evaluate and compare their quality and value. Some modest progress toward this goal is reflected in recent proposed changes in the definition of the Health Plan Employer and Data Information Set (HEDIS) antidepressant medication management measures of optimal practitioner contact, which allows one of the three follow-up telephone contacts to be made by a professional care manager.

Fourth, while it may be optimal to physically locate care managers in primary care practices, it is often not feasible. Alternatives, such as an alliance of several practices employing the needed number of care managers, as depicted in the case studies, can be equally effective. The other major approach is to locate care managers within the health plan office. This arrangement uses telephone contacts exclusively, which permit greater numbers of patients to be reached, although long-term follow-up contacts may be more difficult to maintain. A challenge for all programs that do not use on-site care managers is the development of timely and efficient communications that engage and inform PCPs about their patient's depression care.

Fifth, it is important to examine what level of involvement by mental health specialists is necessary to guarantee quality supervision for the varying types of professionals who serve as care managers.

Sixth, there is no efficient and reliable way of identifying patients who would benefit from depression care management programs. General depression screenings tend to identify too many patients and could overwhelm unprepared care delivery systems unaccustomed to managing depressed patients (Whooley, Stone, \& Soghikian, 2000). Depression registries, unless dutifully maintained, can be unreliable because clinical information is irregularly updated, may not reflect accurate diagnoses, or is not sufficiently sensitive to identify patients with mild or moderate symptoms of depression. The linkage of accurate diagnostic information with an automated entry into a depression registry would clearly facilitate case finding and follow-up.

\section{ACKNOWLEDGMENT}

This work was supported by the Robert Wood Johnson Foundation Depression in Primary Care Incentives Demonstration Program ((\#039959 and \#040861; H.A. Pincus, Principal Investigator).

\section{REFERENCES}

AHCPR. (1993). Depression in Primary Care. Volume 1: Detection and Diagnosis. Volume 2: Treatment of Major Depression (AHCPR Publication Nos. 93-0550 \& 93-0551). Rockville, MD: U.S. Dept. of Health and Human Services, Public Health Service, Agency for Health Care Policy and Research.

Badamgarav, E., Weingarten, S., Henning, J., Knight, K., Hasselblad, V., Gano, A., et al. (2003). Effectiveness of disease management programs in depression: a systematic review. American Journal of Psychiatry, 160(12), 2080-2090. 
Bruce, M., Ten Have, T., Reynolds, C., Katz, I., Schulberg, H., Mulsant, B., et al. (2004). Reducing suicidal ideation and depressive symptoms in depressed older primary care patients: a randomized controlled trial. JAMA, 291(9), 10811091.

Gilbody, S., House, A., \& Sheldon, T. (2001). Routinely administered questionnaires for depression and anxiety: systematic review. British Medical Journal, 322, 406-409.

Goldberg, H., Wagner, E., Fihn, S., Martin, D., Horowitz, C., Christensen, D., et al. (1998). A randomized controlled trial of CQI teams and academic detailing: can they alter compliance with guidelines? Joint Commission Journal on Quality Improvement, 24(3), 130-142.

Hunkeler, E., Meresman, J., Hargreaves, W., Fireman, B., Berman, W., Kirsch, A., et al. (2000). Efficacy of nurse telehealth care and peer support in augmenting treatment of depression in primary care. Archives of Family Medicine, 9(8), 700-708.

Institute of Medicine (2001). Crossing the Quality Chasm. Washington, D.C.: National Academy Press.

Katon, W., Robinson, P., VonKorff, M., Lin, E., Bush, T., Ludman, E., et al. (1996). A multifaceted intervention to improve treatment of depression in primary care. Archives of General Psychiatry, 53, 924-932.

Katon, W., VonKorff, M., Lin, E., Walker, E., Simon, G., Bush, T., et al. (1995). Collaborative management to achieve treatment guidelines. Impact on depression in primary care. JAMA, 273(13), 1026-1031.

Katzelnick, D., Simon, G., Pearson, S., Manning, W., Helstad, C., Henk, H., et al. (2000). Randomized trial of a depression management program in high utilizers of medical care. Archives of Family Medicine, 9(4), 345-351.

Kilbourne, A., Rollman, B., Schulberg, H., Herbeck Belnap, B., \& Pincus, H. (2002). A clinical framework for depression treatment in primary care. Psychiatric Annals, 32, 545-535.

Kroenke, K., Spitzer, R., \& Williams, J. (2001). The PHQ-9: Validity of a brief depression severity measure. Journal of General Internal Medicine, 16(9), 606-613.

Oxman, T., Dietrich, A., \& Schulberg, H. (2003). The depression care manager and mental health specialist as collaborators within primary care. American Journal of Geriatric Psychiatry, 11(5), 507-516.

Pincus, H., Pechura, C., Elinson, L., \& Pettit, A. (2001). Depression in primary care: linking clinical and systems strategies. General Hospital Psychiatry, 23(6), 311-318.

Rollman, B., Hanusa, B., Lowe, H., Gilbert, T., Kapoor, W., \& Schulberg, H. (2002). A randomized trial using computerized decision support to improve the quality of treatment for major depression in primary care. Journal of General Internal Medicine, 17, 493-503.
Rollman, B., Herbeck Belnap, B., Reynolds, C., Schulberg, H., \& Shear, K. (2003). A contemporary protocol to assist primary care physicians in the treatment of panic and generalized anxiety disorders. General Hospital Psychiatry, 25(2), 74-82.

Rost, K., Nutting, P., Smith, J., \& Werner, J. (2000). Designing and implementing a primary care intervention trial to improve the quality and outcome of care for major depression. General Hospital Psychiatry, 22(2), 66-77.

Schulberg, H., Katon, W., Simon, G., \& Rush, A. (1998). Treating major depression in primary care practice: An update of the Agency for Health Care Policy and Research Practice Guidelines. Archives of General Psychiatry, 55(12), 11211127.

Simon, G., \& VonKorff, M. (1995). Recognition, management, and outcomes of depression in primary care. Archives of Family Medicine, 4, 99-105.

Simon, G., VonKorff, M., Rutter, C., \& Wagner, E. (2000). Randomized trial of monitoring, feedback, and management of care by telephone to improve treatment of depression in primary care. British Medical Journal, 320(7234), 550-554.

Unützer, J., Katon, W., Callahan, C., Williams, J., Hunkeler, E., Harpole, L., et al. (2002). Improving mood-promoting access to collaborative treatment. Collaborative care management of late-life depression in the primary care setting: A randomized controlled trial. JAMA, 288(22), 2836-2845.

Von Korff, M., Gruman, J., Schaefer, J., Curry, S., \& Wagner, E. (1997). Collaborative management of chronic illness. Annals of Internal Medicine, 127(12), 1097-1102.

Wagner, E., Austin, B., \& Von Korff, M. (1996). Organizing care for patients with chronic illness. Milbank Quarterly, 74(4), 511-544.

Wagner, E., Davis, C., Schaefer, J., Von Korff, M., \& Austin, B. (1999). A survey of leading chronic disease management programs: Are they consistent with the literature? Managed Care Quarterly, 7(3), 56-66.

Wells, K., Schoenbaum, M., Unützer, J., Lagomasino, I., \& Rubenstein, L. (1999). Quality of care for primary care patients with depression in managed care. Archives of Family Medicine, 8, 529-536.

Wells, K., Sherbourne, C., Schoenbaum, M., Duan, N., Meredith, L., Unützer, J., et al. (2000). Impact of disseminating quality improvement programs for depression in managed primary care: A randomized controlled trial. JAMA, 283(2), 212220.

Whooley, M., Stone, B., \& Soghikian, K. (2000). Randomized trial of case-finding for depression in elderly primary care patients. Journal of General Internal Medicine, 15(5), 293300. 